\title{
Dermatoglyphs in children with mitral valve prolapse
}

\author{
JOHN S H TAY, WILLIAM C L YIP, H K YAP, \\ B W LEE, H B WONG, AND S O CHAY
}

From the Department of Paediatrics, National University of Singapore, Singapore.

SUMMARY The dermatoglyphs of 50 Singapore school children with mitral valve prolapse (MVP) were studied, with special reference to the frequency of digital arches. The MVP was diagnosed clinically and substantiated by two dimensional echocardiography. In the study there were 35 Chinese and 15 Malay children, with ages ranging from 6 to 19 years. Four Chinese children had one or more arches on the digits but none of the Malay children was found to have arches. It was shown that the frequency of arches on the digits was not significantly higher than that among 50 controls (who were shown not to have MVP on two dimensional echocardiography) or when compared with the frequency of arches among the Chinese and Malay population in Singapore $(2.0 \%$ and $2.9 \%$ respectively). No other dermatoglyphic abnormalities (including atd angle) were found.

Mitral valve prolapse (MVP) is a common cardiac valvular abnormality in clinical practice. ${ }^{1}$ Population studies have shown, using ultrasound, that asymptomatic MVP is found in about $18 \%$ of ordinary healthy young females. ${ }^{2}$ There is a female preponderance of nearly $2: 1$ and the frequency of MVP increases linearly with age. ${ }^{1}$ MVP is an aetiologically heterogeneous condition and may be associated with a number of other clinical conditions, such as atrial septal defect, Marfan's syndrome, Ehlers-Danlos syndrome, skeletal anomalies such as pectus excavatum, 'straight back', and severe scoliosis, and coronary artery disease. ${ }^{1}$ While many reviews of this condition are available,${ }^{13}$ there are not many reports of dermatoglyphic findings in children with MVP, and none in Chinese or Malay children with MVP. Swartz et $a l^{4}$ reported an increased frequency of arches $(16.8 \%$ of all digits) in patients with MVP compared with $2.5 \%$ in the control group.

In this paper, the dermatoglyphs of Singapore school children with MVP diagnosed clinically and substantiated by two dimensional echocardiography are reported, with special reference to the frequency of digital arches.

\section{Subjects, methods, and results}

The source of the patients was the school cardiac clinic, Institute of Health, Singapore. All school children in Singapore are examined by a team of doctors and nurses some time in their school life. Children with cardiac murmurs are sent to the school cardiac clinic for further assessment by paediatricians. MVP is diagnosed clinically on the basis of the presence of a mid-systolic click or a late systolic murmur or both. The clinical diagnosis is substantiated by two dimensional echocardiography. This study reports the first 50 school children with MVP in our series.

The diagnostic criteria for MVP on two dimensional echocardiography rested on the demonstration of abnormal superior motion or arching of one or both mitral leaflets above the level of the mitral valve annulus into the left atrium. Two dimensional echocardiography was performed using the ATL Mark III Real Time Ultrasound Cardiology System. Fisher's exact test ${ }^{5}$ was used to evaluate the significance of difference, as the numbers were small.

In our study there were 35 Chinese and 15 Malay children, with ages ranging from 6 to 19 years (mean $12 \cdot 0$, SD $3 \cdot 2$ years). Four Chinese children had one or more arches on the digits (two with one and two with two arches each). None of the Malay children was found to have arches. The results for 50 controls are shown in table 1 . The frequency of arches in the children with MVP is also compared with the frequency of arches among the Chinese and Malay population in Singapore (table 2), ${ }^{67} 2.0 \%$ and $2.9 \%$ respectively. It can be readily shown that in our study children with MVP did not have a significantly higher frequency of arches on the digits 
TABLE 1 Dermatoglyphs in children with MVP.

\begin{tabular}{llllr}
\hline Race & No & \multicolumn{2}{c}{ Total No of arches } & \multicolumn{2}{c}{ Fisher's exact test } \\
\cline { 3 - 5 } & \multicolumn{3}{c}{ Children with MVP } & Controls \\
\hline Chinese & 35 & 6 & 7 & 0.21 (NS) \\
$\begin{array}{l}\text { Malays } \\
\text { Total }\end{array}$ & 50 & 0 & 4 & $46 \cdot 24$ (NS) \\
$\begin{array}{l}\text { Arches as \% of } \\
\text { all digits }\end{array}$ & 6 & 11 & 0.21 (NS) \\
\hline
\end{tabular}

NS $=$ not significant $(p>0 \cdot 05)$.

TABLE 2 Frequency of digital arches in Chinese and Malays.

\begin{tabular}{llll}
\hline Racial group & No & Arches as \% of all digits & Source \\
\hline Chinese & $40(0)$ & $2 \cdot(0 \%$ & Tay $^{6}$ \\
Malays & 281 & $2 \cdot 9 \%$ & Leong $^{7}$ \\
\hline
\end{tabular}

(the figures are actually lower than that in the general population).

The children with MVP were also screened for other dermatoglyphic abnormalities, including atd angle. No significant differences from the general population were found. The mean and standard deviation for the maximal atd angle of the children with MVP were $41 \cdot 8^{\circ} \pm 4 \cdot 3^{\circ}$ (35 Chinese) and $43 \cdot 1^{\circ}$ $\pm 4.8^{\circ}$ (15 Malays). The corresponding values for controls were $41 \cdot 7^{\circ} \pm 4 \cdot 1^{\circ}(100$ Chinese $)$ and $43 \cdot 7^{\circ} \pm$ $5 \cdot 0^{\circ}$ (281 Malays). These differences are not statistically significant.

\section{Discussion}

The results of this study are in marked contrast to the findings of the often quoted study of Schwartz et $a l .{ }^{4}$ Although the Chinese and the Malays have a lower frequency of arches compared to the European races (for example, frequency of arches among the British $^{8}$ is $5.0 \%$ ), an increased frequency of $\%$ arches in Chinese and Malay children with MVP cannot be demonstrated.

\section{References}

1 Ebel TA. Mitral valve prolapse. Adv Pediatr 1978:25:263-325.

2 Markiewicz W, Stoner J, London E. Hunt SA, Popp RL. Mitral valve prolapse in one hundred presumably healthy young females. Circulation 1976;53:464-73.

3 Brown LM. Mitral valve prolapse in children. Adv Pediatr 1978:25:327-48

+ Swartz MH, Herman MV, Teichholz LE. Dermatoglyphic patterns in patients with mitral valve prolapse: a clue to pathogenesis. Am J Cardiol 1976;38:588-93.

5 Armitage P. Statistical methods in medical research. London: Blackwell Scientific Publications, 1971:135.

- Tay JSH. Dermatoglyphics in paediatrics. MD thesis. University of Singapore. 1977

${ }^{7}$ Leong S. Dermatoglyphics of Singapore Malay school children. J Singapore Paediatr Soc 1977:19:51-65.

${ }^{\star}$ Holt SB. The genetics of dermal ridges. Springfield. Illinois: CC Thomas, 1968 .

Correspondence and requests for reprints to Professor John Tay, University Department of Paediatrics, Singapore General Hospital, Outram Road, Singapore 0316, Republic of Singapore. 